\title{
First High Court judgment on sex abuse in Cleveland
}

\author{
CLARE DYER
}

The Middlesbrough child sex abuse controversy looks set to rumble on into the autumn. Last week Mr Justice Hollis gave judgment in the first two of a series of High Court cases involving children whose parents claim that they were wrongly diagnosed as sexually abused, and this week saw the formal opening of the judicial inquiry under Mrs Justice Butler Sloss into Cleveland's sex abuse procedures, which will start hearing evidence on 11 August.

The court cases concerned six children in two families, known only as family A and family B. Like all wardship cases, these had been heard in private, but the judge decided, because of the public outcry over the number of children taken into care in Cleveland in recent months, to give his judgment in open court.

Each of these cases, said the judge, had certain facts in common:

The diagnosis derived from clinical examination alone

The evidence showed that each diagnosis had been based on penetration of the anus

None of the children had had a deprived upbringing

None of the children showed signs of disturbance

None of the children of school age had been noted for anything other than average behaviour

- None of the children who could speak had complained about sexual abuse

No parent had complained about the children being sexually abused

All the parents were caring parents of happy families; there was abundant evidence to support this

- The local authority was not pointing its finger at any particular individuals

- All the children led normal protected lives and all had expressed the wish to go home.

The judge said that the predominant consideration was the welfare of the child, and if there was a risk that a child had been sexually abused in the family environment and that risk was a real or distinct possibility then action had to be taken. On the information received by the local authority it could not be criticised for taking the action it did. But the consequences of that action were serious: it resulted in several children being separated from their families.

Dr Higgs, a consultant paediatrician at Middlesbrough General Hospital since January 1987, relied on an article in the Lancet, ${ }^{1}$ which reported on 35 children with physical signs of buggery. But in all these cases, said the judge, there were other characteristics of sexual abuse such as non-accidental injury, emotional deprivation, disturbed behaviour, overt sexual behaviour, or death in suspicious circumstances. The judge also referred to a letter in the Lancet from Dr Graham Clayden of the department of paediatrics at St Thomas's Hospital, ${ }^{2}$ who runs a special clinic for children with severe constipation. Dr Clayden urged caution in interpreting findings on anal examination.

\section{Two families}

Family A contains three girls-K (aged 7), L (2), and E (9 months). Their father was described as a professional man in a position of trust. E, who suffered from chest infections, was taken to see Dr Higgs on 12 June. She had previously had problems with her hips, and Dr Higgs in examining her hips noticed bruising on her anus. She carried out a further examination and found discoloration of the anus, thickening of the skin of the anal verge, three fissures,

London NW1

CLARE DYER, BA, BLS, legal correspondent and dilatation of the anal sphincter. On examining $\mathrm{L}$ and $\mathrm{K} \mathrm{Dr}$ Higgs also found evidence of anal penetration. One of the signs she recorded when examining $\mathrm{K}$ was scarring of the fourchette. Later in June the children were examined by Dr David Paul, a general practitioner and police surgeon. He found no evidence of sexual abuse.

Family B's children are A, a boy of $14 ; R$, a boy of 12 ; and A, a girl of 10. The girl A had been treated by Dr Wyatt for some time for a recurrent urinary tract infection. On anal examination he found reflex relaxation of the anal sphincter and four fissures. He asked A's mother to bring in the two other children. Both were found to have reflex relaxation and fissures. All three children were later examined by Dr Paul and Dr Raine Roberts, also a general practitioner and police surgeon. They found no evidence to suggest sexual abuse of either R or the girl A. Dr Roberts found slight reflex relaxation on examining $R$ but said in evidence that this might be because $R$ 's anus, like his brother's, was deep set and required considerable pressure even to see it. In the case of the boy A they found symptoms that would be consistent with anal penetration on several occasions -for instance, the anus was slack on digital examination and admitted two fingers which were able to separate-but this could be explained by evacuation of a large stool. There was no evidence of this, but there was evidence that the boy was constipated.

Two consultant paediatricians, Dr Alan Franklin from Essex and Dr Leonard Taitz from Sheffield, also gave evidence. Dr Franklin said that sexual abuse could not be diagnosed simply and solely from a clinical examination; reflex relaxation was a completely nonspecific test. Dr Taitz said that reflex relaxation was a borderline pointer to sexual abuse but not enough on its own.

\section{Judgment}

On all the evidence, the judge asked, was there a real possibility that the children were sexually abused per anum? He said Dr Higgs was clearly wrong about K's fourchette (he referred to Dr Paul's evidence that $\mathrm{K}$ had "the most perfect fourchette imaginable"), but he was far from finding that Dr Higgs and Dr Wyatt were wrong on other findings. There was considerable doubt, however, about the findings of reflex relaxation and dilatation.

The evidence of Dr Paul and Dr Roberts and the other medical evidence taken with other facts cast such doubt on the findings, said the judge, that he was not justified in holding that there was any real possibility that any children had suffered anal penetration except the boy A. At the preliminary hearing on 30 June he had already sent family B's children home. The children had now been at home for a month and he could not see fit to return all of them to care or to split the children up by sending one back. He therefore ordered the wardship to continue with care and control to the parents under a supervision order and with examinations to take place from time to time. He allowed family A's children to go home, but ordered the wardship to continue, with care and control to the parents on their undertaking to take the children to their own general practitioner for three monthly check ups.

Dr Higgs and Dr Wyatt will now have to face the ordeal of a six to eight week public inquiry into their methods and the procedures of Cleveland social services for dealing with cases of sex abuse, which have already been modified as a result of the public outcry and now require a second opinion in suspected cases of sex abuse.

\section{References}

1 Hobbs CJ, Wynne JM. Buggery in childhood-a common syndrome of child abuse. Lance 1986;ii:792-6. 2 Clayden G. Anal appearances and child sex abuse. Lancet 1987;i:620-1. 